Preface

\title{
Age-Related Changes in Thrombosis and Hemostasis
}

\author{
Hau C. Kwaan, MD, FRCP ${ }^{1}$ Brandon J. McMahon, MD ${ }^{1}$ Elaine M. Hylek, MD, MPH ${ }^{2}$ \\ ${ }^{1}$ Feinberg School of Medicine, Northwestern University, Chicago, \\ Illinois \\ ${ }^{2}$ Section of General Internal Medicine, Boston University School of \\ Medicine, Boston, Massachusetts
}

Semin Thromb Hemost 2014;40:619-620.

The global share of older people, aged 60 years or older increased from $9.2 \%$ in 1990 to $11.7 \%$ in 2013 and will continue to grow as a proportion of the world population, reaching $21.1 \%$ by $2050{ }^{1}$

Approximately, one in four deaths worldwide is attributable to stroke or ischemic heart disease. Stroke is the leading cause of disability. Venous thromboembolic disease, pulmonary embolism and deep venous thrombosis, contributes substantially to the global burden of disease. The incidence of arterial and venous thrombosis increases with age. ${ }^{2}$ Given the aging of the population, the impact of thrombotic disorders worldwide is expected to increase dramatically. Likewise, the risk of bleeding in the older population is also higher.

This issue of Seminars in Thrombosis E Hemostasis is devoted to aging and the perturbations that occur with aging that may account for the increased risk for both thrombosis and hemorrhage. To begin with, Favaloro et $\mathrm{al}^{3}$ reviewed the hemostatic markers that are measurable in most clinical hemostasis laboratories, with age-related changes in both the procoagulant and anticoagulant factors, with additional discussions on the need for potential age-adjusted normal ranges. This is well illustrated in D-dimer testing as a means for predicting the recurrence of venous thrombosis, and is extensively reviewed in the next article by Lippi et al. ${ }^{4}$ Among those hemostasis factors affected most by age-related changes is the increase in von Willebrand factor. The implications of such changes on the risk of thrombosis and in the treatment of von Willebrand disease are therefore discussed by Konkle. ${ }^{5}$

One of the often underrecognized modulators of hemostasis and an important pathogenic factor in vascular diseases is plasminogen activator inhibitor 1 (PAI-1). Recently, PAI1 was found to have a role in senescence. Eren et al provide both the background and genetic basis of the association between PAI-1 and senescence and further demonstrate how PAI-1 knockout can restore the shortened life span of the Klotho $(k l / k l)$ mice. $^{6}$ The changes in PAI-1 expression with aging and elevated PAI-1 in several age-related pathologies
Address for correspondence School of Medicine, Northwestern University, Chicago, IL 60611 (e-mail: h-kwaan@northwestern. edu). Hau C. Kwaan, MD, FRCP, Feinberg
Issue Theme Age-Related Changes in Thrombosis and Hemostasis; Guest Editors: Hau C. Kwaan, MD, FRCP, Brandon J. McMahon, MD, and Elaine M. Hylek, MD, MPH. including malignancies, insulin resistance, inflammation, and stress are then reviewed by Yamamoto et al. ${ }^{7}$ These authors also provided findings showing how increased PAI- 1 contributes to the progression of aging by promoting fibrosis and thrombosis.

Platelets, likewise, undergo changes with aging. Among these changes is the decreased antiaggregation response to nitric oxide, a phenomenon described by Procter et al. ${ }^{8}$ Their article is followed by a discussion by Schlaudecker and Becker of the increased inflammatory responses in aging contributing to the elevated thrombophilia. ${ }^{9}$

The remaining part of this issue is devoted to situations seen in the clinical practice in the aging population, starting with a review by Cunningham et al of the role of thrombogenic microparticles in autoimmune diseases, including rheumatoid arthritis, systemic sclerosis, and systemic lupus erythematosus affecting older individuals. ${ }^{10}$ Next is the discussion by McMahon and Kwaan on the increased hazards in the older patients with immune thrombocytopenic purpura. Older adults are also more often taking multiple drugs and are at higher risk for drug-induced thrombocytopenia. ${ }^{11}$ Anticoagulants are more often used in older than in younger individuals and their administration poses a greater risk as well, as pointed out by Ko and Hylek. ${ }^{12}$ Another important but often forgotten aspect in maintaining good health in aging is the quality of nutrition, ably reviewed by Dawson and Axford. ${ }^{13}$ The last, but not the least, article was provided by Ichinose on acquired factor XIII/13 deficiency as an uncommon autoimmune disorder more often seen in older individuals than in the young, likely another manifestation of immunosenescense. $^{14}$

Advances in our basic understanding of these age-related changes will help to improve interventions for this increased vulnerability as we age. Elucidating clinical patterns and environmental triggers that compound these risks will augment efforts to translate discovery to the bedside. We trust that our readers will be as excited as we are in exploring these efforts.
Copyright $\odot 2014$ by Thieme Medical Publishers, Inc., 333 Seventh Avenue, New York, NY 10001, USA. Tel: +1(212) 584-4662.
DOI http://dx.doi.org/ 10.1055/s-0034-1390152. ISSN 0094-6176. 


\section{References}

1 United Nations DoEaSA, Population Division World Population Ageing. ST/ESA/SERA/348; 2013

2 Engbers MJ, van Hylckama Vlieg A, Rosendaal FR. Venous thrombosis in the elderly: incidence, risk factors and risk groups. J Thromb Haemost 2010;8(10):2105-2112

3 Favaloro E, Franchini M, Lippi G. Aging hemostasis: changes to laboratory markers of hemostasis as we age-a narrative review. Semin Thromb Hemost 2014;40(6):621-633

4 Lippi G, Favaloro EJ, Cervellin G. A review of the value of D-dimer testing for prediction of recurrent venous thromboembolism with increasing age. Semin Thromb Hemost 2014;40(6):634-639

5 Konkle B. Von Willebrand factor and aging. Semin Thromb Hemost 2014;40(6):640-644

6 Eren M, Boe AE, Klayachko EA, Vaughan DE. Role of plasminogen activator inhibitor-1 in senescence and aging. Semin Thromb Hemost 2014;40(6):645-651

7 Yamamoto K, Takeshita K, Saito H. Plasminogen activator inhibitor 1 in aging. Semin Thromb Hemost 2014;40:652-659

8 Procter NEK, Chong C-R, Sverdlov AL, Chan WPA, Chirkov YY, Horowitz JD. Aging of platelet nitric oxide signaling: pathogenesis, clinical implications and therapeutics. Semin Thromb Hemost 2014;40(6):660-668

9 Schlaudecker J, Becker R. Inflammatory response and thrombosis in older individuals. Semin Thromb Hemost 2014;40(6): 669-674

10 Cunningham M, Marks N, Barnado A, Wirth JR, Gilkeson G, Markiewicz M. Are microparticles the missing link between thrombosis and autoimmune diseases? Involvement in selected rheumatologic diseases. Semin Thromb Hemost 2014;40(6): 675-681

11 McMahon BJ, Kwaan HC. Thrombocytopenia in older adults. Semin Thromb Hemost 2014;40(6):682-687

12 Ko D, Hylek EM. Anticoagulation in the older adult: optimizing benefit and reducing risk. Semin Thromb Hemost 2014;40(6): 688-694

13 Dawson B, Axford S. Nutrition as a part of healthy aging and reducing cardiovascular risk: improving functionality in later life using quality protein, with optimized timing and distribution. Semin Thromb Hemost 2014;40(6):695-703

14 Ichinose A. Inhibitors of factor XIII/13 in older patients. Semin Thromb Hemost 2014;40(6):704-711 